\title{
Microvillus inclusion disease
}

INSERM

\section{Source}

INSERM. (1999). Orphanet: an online rare disease and orphan drug data base. Microvillus inclusion disease. ORPHA:2290

Microvillus inclusion disease (MVID) is a very rare and severe intestinal disease characterized by intractable neonatal secretory diarrhea persisting at bowel rest and specific histological features of the intestinal epithelium. 